\title{
PAR recognition by multiple reader domains of PARP1 allosterically regulates the DNA-dependent activities and independently stimulates the catalytic activity of PARP1
}

Waghela Deeksha, Suman Abhishek, and Eerappa Rajakumara*

Macromolecular Structural Biology Lab, Department of Biotechnology, Indian Institute of Technology Hyderabad, Kandi, Sangareddy, Telangana 502284, India

*To whom correspondence should be addressed. Tel: +91-40-23017002; Email: eraj@bt.iith.ac.in 


\begin{abstract}
Poly(ADP-ribosyl)ation is a post translational modification, predominantly catalyzed by Poly(ADP-ribose) polymerase 1 (PARP1) in response to DNA damage, mediating the DNA repair process to maintain genomic integrity. Single strand (SSB) and double strand (DSB) DNA breaks are bonafide stimulators of PARP1 activity. We identified that, in addition, single strand (ss) DNA also binds and stimulates the PARP1 activity. Poly(ADP-ribose) (PAR) is chemically similar to ssDNA. However, PAR mediated PARP1 regulation remains unexplored. Here, we report ZnF3, BRCT and WGR, hitherto uncharacterized, as PAR-specific reader domains of PARP1. Surprisingly, these domains recognize PARylated protein with a higher affinity compared to PAR, but do not bind to DNA. Conversely, N-terminal domains, ZnF1 and ZnF2, of PARP1 recognize DNA but not PAR. Further competition binding studies suggest that PAR binding, allosterically releases DNA from PARP1. Unexpectedly, PAR showed catalytic stimulation of PARP1 but hampers the DNA dependent stimulation. Altogether, our work discovers dedicated PAR and DNA reader domains of the PARP1, and uncovers a novel mechanism of allosteric stimulation of the catalytic activity of PARP1 but retardation of DNA-dependent activities of PARP1 by its catalytic product PAR.
\end{abstract}

Keywords: Poly(ADP-ribose) polymerase, DNA repair, PAR reader domains, Poly(ADP-ribose), Allosteric regulation 


\section{INTRODUCTION}

Poly(ADP-ribose) polymerase 1 (PARP1), an abundant nuclear enzyme often referred to as "genome guardian", plays a crucial role in maintaining genome integrity (1). It is involved in several cellular functions, including DNA damage repair (2-6), regulation of chromatin structure (7-9), transcription (10-12) and apoptosis (13, 14). PARP1, the founding member and the most studied enzyme among the PARP family, is a multidomain protein consisting of three zinc finger domains, ZnF1, ZnF2 and ZnF3 at the $\mathrm{N}$-terminal, followed by the BRCT (Breast cancer associated C-terminal) domain and the WGR (Trp-Gly-Arg rich) domain in the central region, and the catalytic (CAT) domain at the C-terminal, which comprises the helical sub-domain (HD) and the signature ADP-ribosyl transferase (ART) sub-domain (Figure 1A). PARP1 has been shown to recognize different types of damaged DNA by different combinatorial sets of $\mathrm{ZnFs}$. The $\mathrm{ZnF1}$ and $\mathrm{ZnF3}$ together bind to a double strand break (DSB) whereas $\mathrm{ZnF1}$ and ZnF2 bind to a single strand break (SSB) DNA (15-19). However, the involvement of PARP1 domains, either individual or in combination, has not been studied extensively.

Further, recognition of damaged DNA by zinc finger domains of PARP1 induces a global conformational change in the protein, i.e., spatial re-organization of the domains, which facilitates the positioning of CAT domain close to the automodification (AD) region, which comprises the C-terminal region of BRCT domain and the loop connecting the BRCT and WGR domains $(20,21)$. PARP1, then, catalyzes a series of covalent addition of $A D P$-ribose (ADPr) on the $A D$ region using $N^{+} D^{+}$as a co-factor to form a long, linear or branched, chain of poly(ADP-ribose) also referred to as PAR, consisting of $>200$ units of negatively charged $A D P r$, and the phenomenon being known as PARylation (Figure 1B) $(16,22)$. PARP1 catalyzes the PARylation activity not only on itself (self-PARylation) but also on the other target proteins (transPARylation) on the target residues including aspartate, glutamate, lysine, serine, arginine, etc. (23-27).

PAR serves as a docking platform for recruitment of DNA damage repair proteins. Several domains in various proteins have been identified to bind PAR. Besides the classical, well characterized PAR reader modules, macro domain, WWE, PBZ (PAR binding Zinc finger), PBM (PAR binding motif), from PAR hydrolysing enzymes, there are other domains which have been reported to recognize PAR. These include FHA (Fork head associated) domain, OB (oligonucleotide or oligosaccharide binding fold), BRCT which recognize ADPr, etc. $(28,29)$. Recently, PARP2 was reported to recognize PAR through unstructured $\mathrm{N}$-terminal region, which also regulates its activity (30).

Both, PARP1 and PARP2, are allosterically regulated by DNA binding, resulting in activation of the enzymatic activity of the proteins $(31,32)$. Almost all kinds of DNA, such as, DSB, SSB, overhangs, cruciform and hairpin, with or without 5'-Phosphate (5'P), are able to stimulate the activity of PARP1, although to different extents (33). PARP1 is also known to be activated upon binding to different types of RNA like snoRNA, pre-mRNA and therefore involved in RNA biogenesis (34), alternative splicing of mRNA (35), etc. Although the degree of activation of PARP1 upon RNA binding is less compared to DNA binding (30). Also, one of the study shows that there are RNAs which could bind non-specifically to PARP1 and PARP2 but could not activate them (36). Proteins such as histones (37), HPF1 (38), mH2A1.1 (39), HMGN1 (40), XPA (41), NEIL1 (42), OGG1 (43), DDB2 (44), p53 (45), ERK2 (46), Sam68 (47), YB-1 (48), C12orf48 (49), etc. physically interact with the PARP1 and regulate the 
PARP1 activities. In addition, interaction of PARP1 with other proteins or another PARP1 molecule is strengthened significantly in presence of DNA $(42,43)$ or PAR (50) owing to the involvement of additional protein domains. Since chemical nature of PAR polymer is very similar to nucleic acid molecules, like RNA / DNA (Supplementary Figure 1), we hypothesize that domains which recognize DNA may also bind to PAR.

Here, using biophysical approaches, we have established the role of different domains of PARP1, individual and in combination, in recognition of PAR and DNA. Our studies show that different sets of PARP1 domains mutually and selectively recognize the PAR, and damaged and single strand DNAs. Our work also reveals that PAR partially inhibits the DNA dependent catalytic activity of full-length PARP1 (PARP1 $1_{\mathrm{FL}}$ ) and also acts as a stimulator of PARP1 $\mathrm{FL}$ activity. Further, we elucidate the possible mechanism of DNA dislodging from PARP1 upon PAR binding. Our studies also establish the single stranded DNA (ssDNA) as an additional regulator of PARP1 which may have further implications yet to be explored.

\section{MATERIALS AND METHODS}

\section{Cloning, expression and purification of PARP1 $\mathrm{FL}$, variants of PARP1, PARP2 and PNC1}

The full length human PARP1 (aa 1-1014) cDNA in pET28-a(+) has been purchased from GenScript, USA.. PARP1FL (aa: 1-1014), ZnF1-BRCT (aa: 1-494), WGR-CAT (aa: 518-1014) and individual domain constructs were generated by cloning the sequence in bacterial expression vector pRSFDuet-1 vector between Sacl and Xhol restriction sites. Domain length of individual constructs is same as given in Langelier et al., 2011 (51). E. coli Rosetta 2 (DE3) were transformed with the constructs for expression. An hour before inducing the culture with $0.2 \mathrm{mM}$ IPTG, $100 \mu \mathrm{M} \mathrm{ZnSO} 4$ was added. Culture was induced at $16^{\circ} \mathrm{C}$ for $16-18 \mathrm{~h}$, then harvested. The pellet was resuspended in lysis buffer containing $500 \mathrm{mM} \mathrm{NaCl}, 50 \mathrm{mM}$ HEPES pH 7.5, 20mM Imidazole and $3 \mathrm{mM} \beta$-mercaptoethanol Protease inhibitor cocktail tablets (Pierce ${ }^{\mathrm{TM}}$ Protease Inhibitor, Thermo Scientific) were added in case of PARP1FL only. The cell suspension was sonicated, the lysate was clarified by centrifugation and the proteins were purified in 3-steps. First, supernatant was passed through Ni-NTA affinity column (5ml, HisTrap column, GE Healthcare), followed by ion exchange Heparin column (HiTrap Heparin HP, GE Healthcare) with salt gradient of $(250-1000 \mathrm{mM} \mathrm{NaCl}$ for PARP1 $1_{\mathrm{FL}}$ and $50 \mathrm{mM}-1000 \mathrm{mM} \mathrm{NaCl}$ for all other constructs) and finally through gel filtration (16/600 200pg, GE Healthcare) column pre-equilibrated with buffer (150mM $\mathrm{NaCl}$ (for PARP1 $1_{\mathrm{FL}}$ ) and $50 \mathrm{mM} \mathrm{NaCl}$ (for all other constructs), 10mM HEPES, $2 \%$ Glycerol and $2 \mathrm{mM} \beta$-mercaptoethanol). Purified proteins were concentrated, flash frozen and stored at $-80^{\circ} \mathrm{C}$.

The full length human PARP2 isoform 2 cloned in pET28-a(+) was generously gifted by Dr. John Pascal. PARP2 was expressed in E. coli BL21(DE3) at conditions same as PARP1 $1_{\mathrm{FL}}$ and purified using Ni-NTA affinity and ion-exchange chromatography using the protocol mentioned for PARP1FL.

PNC1 from Saccharomyces cerevisiae cloned in pET41-b(+) was obtained as a generous gift from Prof. Antonio Barrientos. E. coli Rosetta 2(DE3) were transformed with the construct for expressing the protein. Culture was induced with $0.1 \mathrm{mM}$ IPTG at $18^{\circ} \mathrm{C}$. Cells were harvested after $16 \mathrm{~h}$ and resuspended in buffer containing $50 \mathrm{mM}$ Tris- $\mathrm{HCl} \mathrm{pH} 8.0,500 \mathrm{mM} \mathrm{NaCl}, 10 \mathrm{mM}$ imidazole and $10 \%$ glycerol. Cell suspension was sonicated, and lysate was centrifuged at $4^{\circ} \mathrm{C}$. Obtained supernatant was loaded onto Ni-NTA affinity column (5ml, HisTrap column, GE Healthcare) and eluted by step 
gradient of $10-400 \mathrm{mM}$ Imidazole in the same buffer. Fractions were pooled and passed through gel filtration column (16/600 75pg, GE Healthcare) pre-equilibrated with $20 \mathrm{mM}$ Tris $\mathrm{pH} 8.0,150 \mathrm{mM} \mathrm{NaCl}, 1.5 \mathrm{mM} \beta$-mercaptoethanol and $1 \%$ glycerol. Purified PNC1 was concentrated, flash frozen and stored at $-80^{\circ} \mathrm{C}$. (52).

\section{PAR generation and purification and fractionation}

PAR was generated by performing automodification reaction of PARP1 $\mathrm{FL}$, cleaved from the protein and purified according to the protocol given in Lin et al., 2018 (53). Obtained PAR was diluted with $20 \mathrm{mM}$ Tris-HCl buffer $\mathrm{pH} 7.5$ and was loaded into Resource $Q$ anion exchange $1 \mathrm{ml}$ column (GE Healthcare) for fractionation with a linear gradient of $0-1 \mathrm{M} \mathrm{NaCl}$ at $0.25 \mathrm{ml} / \mathrm{min}$ flow rate, with FPLC UV filter set at $254 \mathrm{~nm}$. Obtained separate fractions were precipitated by adding $1 / 10^{\text {th }}$ volume of $3 \mathrm{M}$ sodium acetate $\mathrm{pH} 5.2$, and 2.5 times volume of ice-cold $100 \%$ ethanol. After incubating overnight in $-20^{\circ} \mathrm{C}$, the precipitates were separated by centrifugation at $15000 \mathrm{~g}$ for 30 $\min$ at $4^{\circ} \mathrm{C}$. The pellet was washed with $1 \mathrm{ml}$ of $70 \%$ ethanol twice by centrifugation at $15000 \mathrm{~g}$ for $10 \mathrm{~min}$. Pellet was air dried and resuspended in $20 \mu \mathrm{l}$ of autoclaved distilled water. Concentration was calculated by taking the absorbance at $258 \mathrm{~nm}$ and taking the molar extinction coefficient of $A D P r 13.5 \mathrm{mM}^{-1} \mathrm{~cm}^{-1}$.

\section{Nucleic acids generation and annealing}

HPLC purified lyophilized DNA oligonucleotides (listed in Supplementary Table 1) and complementary strands were purchased from oligo synthesis facility of W.M. Keck Foundation, Yale School of Medicine, USA and dissolved in a buffer containing $10 \mathrm{mM}$ Tris- $\mathrm{Cl}$ ( $\mathrm{pH} 7.5), 50 \mathrm{mM} \mathrm{NaCl}$ and $3 \mathrm{mM} \mathrm{MgCl}_{2}$. DSB DNA as prepared by mixing the complementary strands in an equimolar ratio. A dumbbell-forming 45-mer DNA oligonucleotide was used to make SSB DNA. DSB and SSB DNA were kept for annealing at $95^{\circ} \mathrm{C}$ for 5 minutes and cooled at $4^{\circ} \mathrm{C}$ for overnight. ssDNA and $5^{\prime} \mathrm{P}$ ssDNA were dissolved in same buffer and used as it is.

\section{Generation of PARylated PARP2}

PARylated PARP2 was generated using the same automodification protocol as used for PARP1FL with incubation time of $30 \mathrm{~min}$, after which the reaction mixture was passed through the salt exchange column (HiPrep 16/10 Desalting, GE Healthcare) with FPLC UV filter set at $254 \mathrm{~nm}$ and then concentrated using $10 \mathrm{kDa}$ concentrator. Concentration was calculated by subtracting the measured absorbance at $258 \mathrm{~nm}$ and $280 \mathrm{~nm}$ of the final concentrated sample and before keeping for automodification reaction and taking the molar extinction coefficient of $A D P r 13.5 \mathrm{mM}^{-1} \mathrm{~cm}^{-1}$.

\section{Isothermal Titration Calorimetry (ITC) binding studies}

ITC binding studies were carried out at $25^{\circ} \mathrm{C}$ using LV Affinity ITC (TA Instruments). Reference cell was filled with deionized water. For all binding studies, DNA $(5-10 \mu \mathrm{M})$ (Supplementary Table 1), PAR $(10-20 \mu \mathrm{M})$ or PARylated PARP2 (10-20 $\mu \mathrm{M}$, concentration according to 10 mer PAR) were added in cell $(350 \mu l)$ and PARP1 domains (0.1-0.3 mM) were taken in syringe. 20 consecutive injections of $2.5 \mu \mathrm{l}$ at an interval of 120 s were performed while stirring the cell content at 125rpm. Analysis and processing of the binding isotherm was performed using NanoAnalyse software provided by TA instruments. For binding study with ADPr, $0.1 \mathrm{mM}$ of either BRCT, WGR or ZnF1-BRCT was taken in cell and $1 \mathrm{mM}$ ADPr in syringe.

\section{Fluorescence Polarization (FP) studies}


Fluorescence polarization DNA binding studies were performed in gel filtration buffer using SpectraMaxID5 (Molecular devices). Fluorophore, 5-FAM, labelled DNAs (Supplementary Table 1) were used for binding and competition binding studies. For DNA binding studies, 20nM fluorophore labelled DNA was used and protein concentration was varied from $0.2 \mathrm{nM}$ to $2 \mu \mathrm{M}$ ). For the competition binding assay, 40 $\mathrm{nM}$ of protein was incubated with the $20 \mathrm{nM}$ of probe DNA and PAR was added in varying concentration of $2.5 \mathrm{nM}$ to $5 \mu \mathrm{M}$ at room temperature for $45 \mathrm{~min}$. The FP values were plotted against the variable entity into a nonlinear regression model. The Ki were calculated from Binding-Competitive model in GraphPad Prism. The reported Ki and $K_{D}$ represent an average of three independent experiments.

\section{PNC1-OPT assay}

PNC1-OPT assay was performed to measure the amount of NAD+ consumed during PARylation by PARP1FL (54). Reactions were performed in a 96-well plate with one reaction in the absence of NAD+ to account for background fluorescence. PARylation reaction was performed at room temperature by adding $1 \mu \mathrm{M}$ PARP1FL, DNA $1 \mu \mathrm{M}$ and/ or PAR $-10 \mu \mathrm{M}$ ) and $5 \mathrm{mM}$ nicotinamide in buffer $(25 \mathrm{mM}$ HEPES pH 8.0, $140 \mathrm{mM} \mathrm{KCl}$, $8 \mathrm{mM} \mathrm{MgCl} 2,50 \mu \mathrm{g} / \mathrm{ml} \mathrm{BSA}, 0.02 \mathrm{mM}$ TCEP, 4\% glycerol, and $11.4 \mathrm{mM} \mathrm{ME})$. The reactions were quenched with $5 \mathrm{mM}$ benzamide after $30 \mathrm{~s}, 45 \mathrm{~s}, 1 \mathrm{~min}, 2 \mathrm{~min}, 5 \mathrm{~min}$, $10 \mathrm{~min}, 20 \mathrm{~min}$ and $30 \mathrm{~min}$. Purified yPnc1 enzyme was added at $20 \mu \mathrm{g} / \mathrm{ml}$ to the quenched reactions. The reactions were incubated at $37^{\circ} \mathrm{C}$ for an hour. During the incubation period, OPT developer reagent $(10 \mathrm{mM}$ ortho-pthalaldehyde (OPT), 30\% ethanol and $10 \mathrm{mM}$ dithiothreitol) was prewarmed at $37 \circ \mathrm{C}$ in the dark. Following the incubation period, $50 \mu \mathrm{l}$ of OPT developer reagent was added to each reaction under dim light. The reactions were incubated at room temperature for 1 hour at $45 \mathrm{rpm}$ on an orbital shaker. The plates were transferred to a plate reader (EnSpire ${ }^{\mathrm{TM}}$ Multimode Plate Reader by PerkinEImer, Inc.) with monochromators set to excitation at $420 \mathrm{~nm}$ and emission at $450 \mathrm{~nm}$. Using the arbitrary fluorescence unit (AFU) readings for each reaction, the net fluorescence was calculated for each sample by subtracting the fluorescence of the control reaction (-NAD+) from the experimental reaction, $F($ corrected $)=F($ sample $)-F(-N A D+)$. The resulting value is proportional to the amount of nicotinamide produced during the PARylation reaction and therefore the amount of NAD+ consumed. Serially diluted nicotinamide was used as a standard curve. Data analysis was performed from three independent reactions. Error bars indicate standard deviation of three independent experiments.

\section{RESULTS}

\section{Binding studies of Zn-finger domains of PARP1 to PAR}

Our isothermal titration calorimetry (ITC) binding studies of PAR with individual zinc finger domains of PARP1 showed that among the zinc fingers ( $\mathrm{nnF}), \mathrm{ZnF} 3$ exhibited a highest binding affinity towards PAR with a molar dissociation constant $\left(K_{D}\right)$ of 2.8 $\mu \mathrm{M}$. Compared to $\mathrm{ZnF3}, \mathrm{ZnF} 1$ showed $\sim 53$ times less binding affinity $\left(\mathrm{K}_{\mathrm{D}} \sim 150 \mu \mathrm{M}\right)$, and $\mathrm{ZnF} 2$ exhibited even weaker binding (KD could not be determined) (Figure 1C-E). 


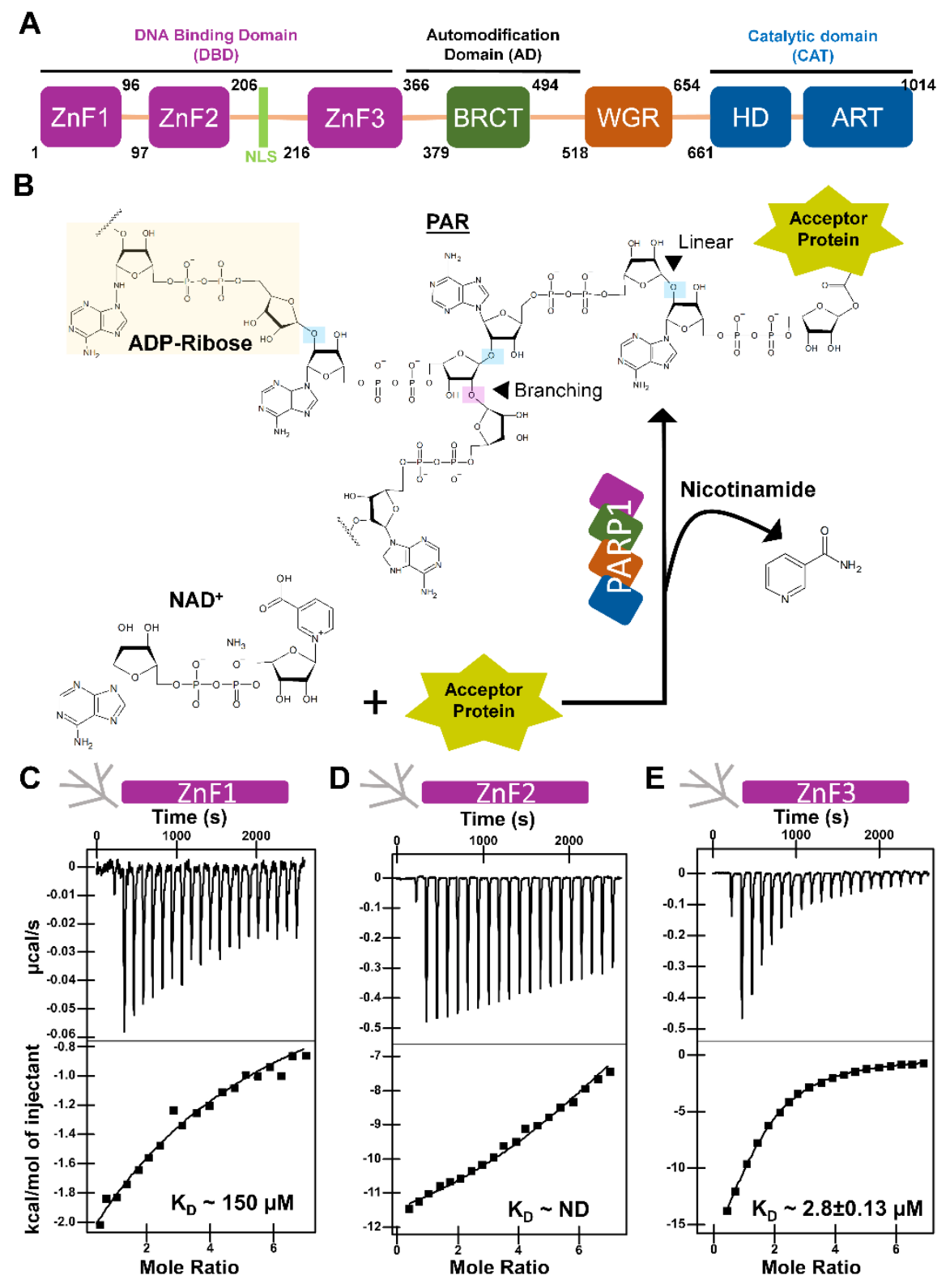

Figure 1. Domain architecture of PARP1 and PAR binding studies. Schematic representation of $(A)$ domain architecture of $P A R P 1_{F L}$ and (B) Poly(ADP-ribosyl)ation (PARylation) reaction catalyzed by PARP1. ITC plots of PAR titrated with (C) ZnF1, (D) ZnF2 and (E) ZnF3. ND stands for 'Not determined'. In the figures 1 to 2 branched tree on the top of ITC panel indicates the PAR.

\section{WGR and BRCT domains of PARP1 bind to PAR}

We performed ITC binding studies of PAR with BRCT and WGR domain of PARP1. Surprisingly, the WGR domain didn't only bind to PAR but showed a high binding affinity with a $K_{D}$ of $5.1 \mu \mathrm{M}$ (Figure $2 \mathrm{~A}$ ). BRCT domain's binding affinity is similar to WGR's $\left(K_{D} \sim 4.2 \mu \mathrm{M}\right)$ (Figure 2B). On the contrary, neither WGR nor BRCT domains recognize ADPr, the repeating unit of PAR (Supplementary Figure 2A-B).

\section{Calorimetric binding studies of combination of PARP1 domains to PAR}

To determine the cooperativity in PARP1 domains to bind to PAR, we performed binding studies. Our ITC data show that ZnF1-BRCT binds to PAR with several folds 
more binding affinity compared to individual domains, i.e., $\mathrm{K}_{\mathrm{D}} \sim 0.6 \mu \mathrm{M}$ (Figure $2 \mathrm{C}$ ). On the other hand, ZnF1-BRCT also did not bind to ADPr (Supplementary Figure 2C). WGR-CAT showed a KD of 2.7 $\mu \mathrm{M}$ for PAR (Supplementary Figure 3A) whereas, the catalytic domain (CAT) showed a weaker affinity $\left(K_{D} \sim 39.1 \mu \mathrm{M}\right)$ (Supplementary Figure 3B).

\section{Calorimetric binding studies of PARP1 domains to PARylated proteins}

Our ITC based binding studies showed that the WGR and BRCT domains of PARP1 bind to PARylated PARP2 with a $\mathrm{K}_{\mathrm{D}}$ of 2.9 and $2.4 \mu \mathrm{M}$, respectively (Figure $2 \mathrm{D}-\mathrm{E}$ ). Further, titration of PARylated PARP2 against quadruple ZnF1-BRCT domain of PARP1 showed a $K_{D}$ of $0.2 \mu \mathrm{M}$ (Figure $2 F$ ). While these domains alone did not bind to un-PARylated PARP2 (Supplementary Figure 4).
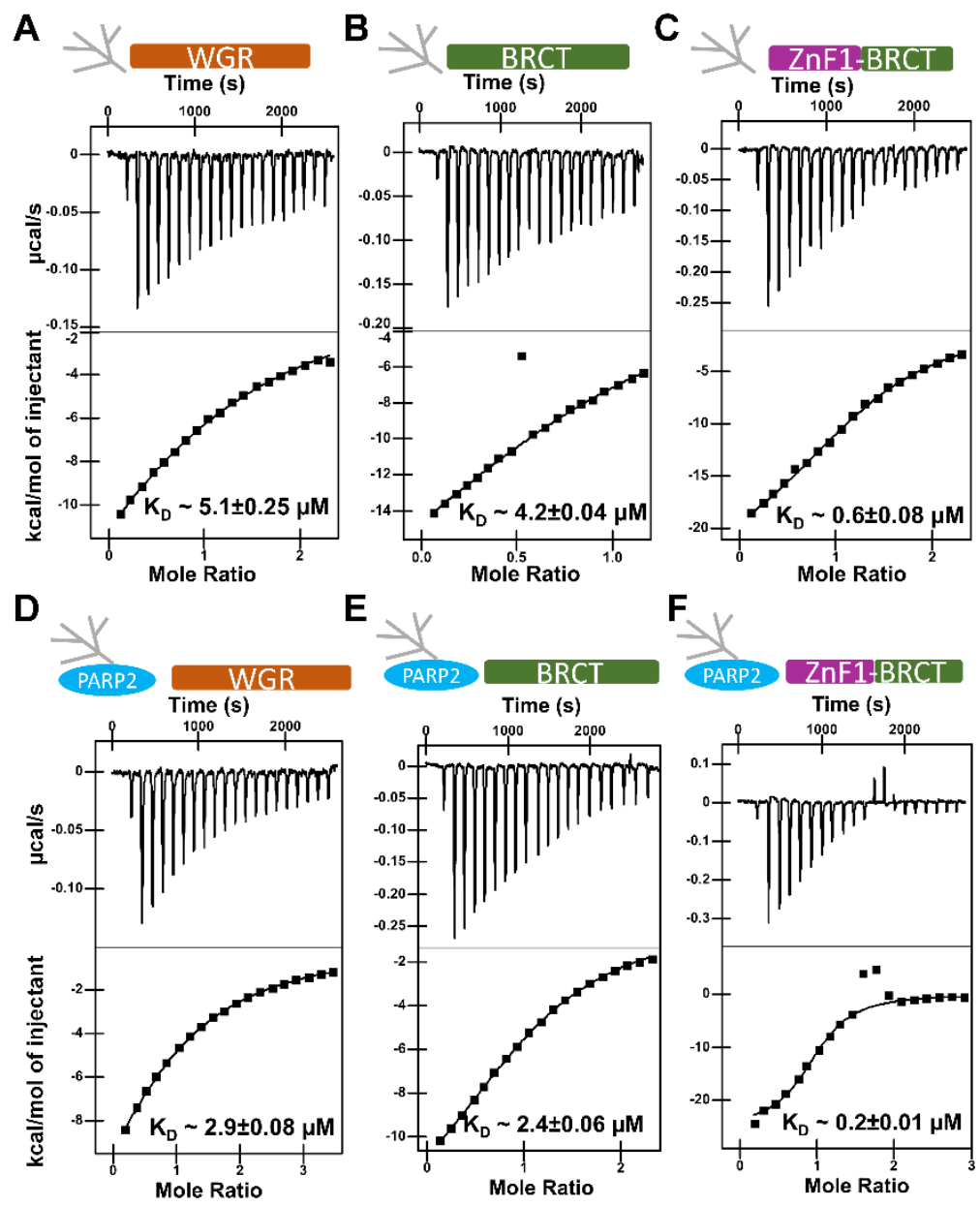

Figure 2. ITC binding studies of PAR with (A) WGR (B) BRCT (C) ZnF1-BRCT, and PARylated PARP2 with (D) WGR (E) BRCT (F) ZnF1-BRCT.

\section{Calorimetric studies of the ssDNA binding specificity of the PARP1 domains}

The calorimetric binding studies of individual domains of PARP1 with a single strand DNA (ssDNA) and a ssDNA with 5'-phosphate (5'P-ssDNA) showed that among zinc fingers, $\mathrm{ZnF} 2$ binds to both the DNAs with highest and almost a similar affinity $\left(\mathrm{K}_{\mathrm{D}} \sim 4.3\right.$ $\mu \mathrm{M}$ ), whereas $\mathrm{ZnF1}$ exhibited a $\mathrm{K}_{\mathrm{D}}$ of $6.3 \mu \mathrm{M}$ for $5^{\prime} \mathrm{P}$-ssDNA and a $\mathrm{K}_{\mathrm{D}}$ of $5.4 \mu \mathrm{M}$ for ssDNA. (Figure 3A-D). ZnF3 binds neither ssDNA nor 5'P-ssDNA (Figure 3E-F). 
Whereas WGR binds neither DSB nor SSB DNA, and also does not exhibit binding towards 5'P-ssDNA and ssDNA (Supplementary Figure 5).
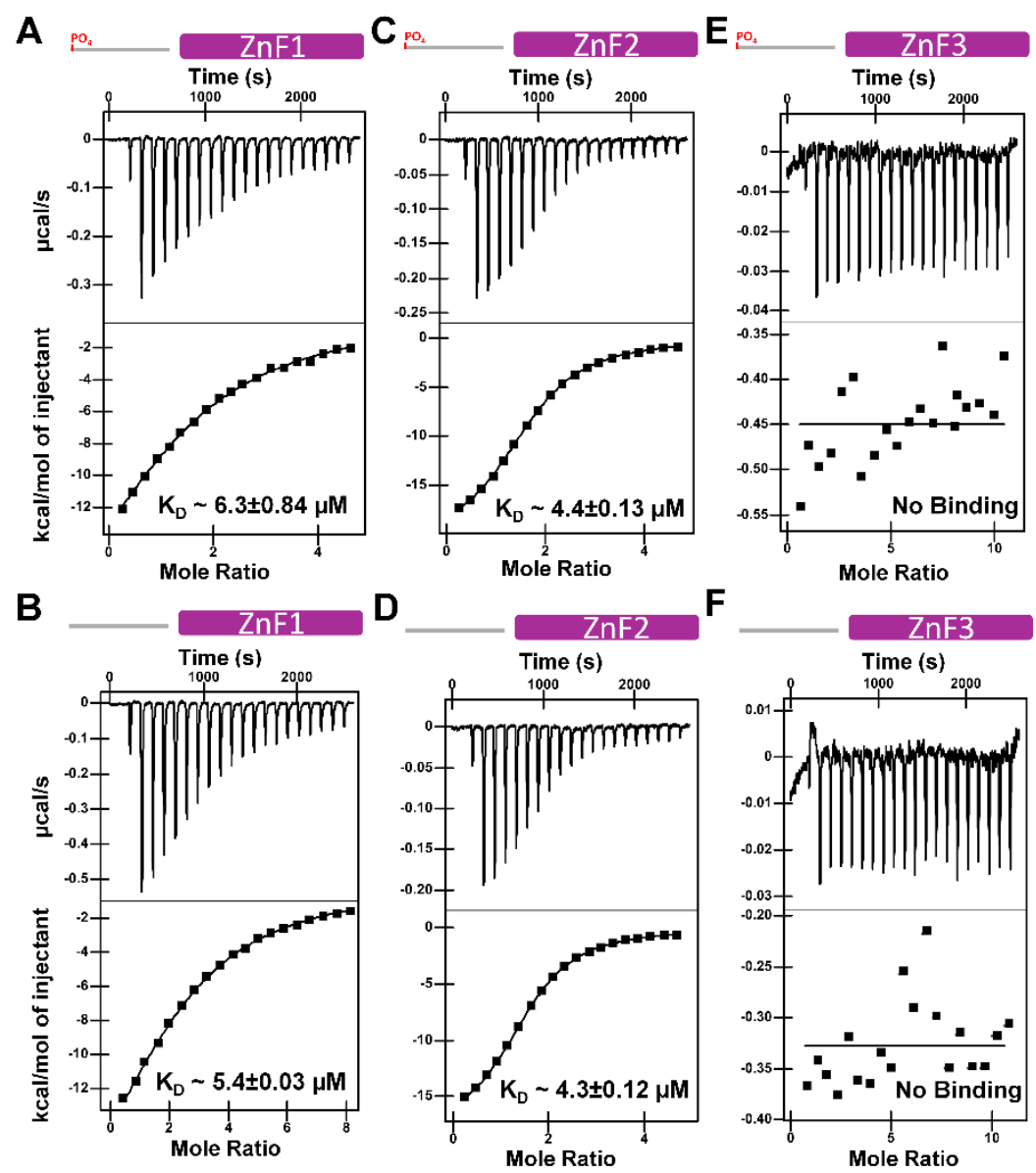

Figure 3. ITC binding studies between single stranded DNAs, with and without ${ }^{\prime}{ }^{\prime} P$, and zinc finger domains of PARP1. ITC plot of ZnF1 binding to (A) 5'P-ssDNA and (B) SSDNA; ZnF2 binding to (C) 5'P-ssDNA and (D) ssDNA; and ZnF3 binding to (E) 5'P-ssDNA and (F) ssDNA.

\section{Competition binding studies of PAR and different DNAs to ZnF1-BRCT quadruple domains of PARP1}

We carried out fluorescence polarization (FP) based competition binding studies to investigate whether PAR can compete with different damaged DNAs to bind $\mathrm{ZnF1}$ BRCT quadruple domains. Our FP binding studies shown that ZnF1-BRCT binds to DSB, SSB and 5'P-sSDNA with a $\mathrm{K}_{\mathrm{D}}$ of $37.8 \mathrm{nM}, 43.8 \mathrm{nM}$ and $83.6 \mathrm{nM}$, respectively (Figure $4 \mathrm{~A}-\mathrm{C}$ ). ITC binding studies underestimated the binding affinity between $\mathrm{ZnF1}$ BRCT and above DNAs, but relative binding affinities are highly correlated (Supplementary Figure 6 and Figure 4). Competition FP assays were performed to evaluate the displacement of the fluorophore labelled bound DNA probe by PAR. The molar equilibrium dissociation constant $(K I)$ of the unlabeled competitor PAR was determined to be $104.8 \mathrm{nM}, 47.3 \mathrm{nM}$ and $50.3 \mathrm{nM}$, respectively for DSB, SSB and 5'PssDNA bound to ZnF1-BRCT (Figure $5 \mathrm{~A}-\mathrm{C}$ ). 

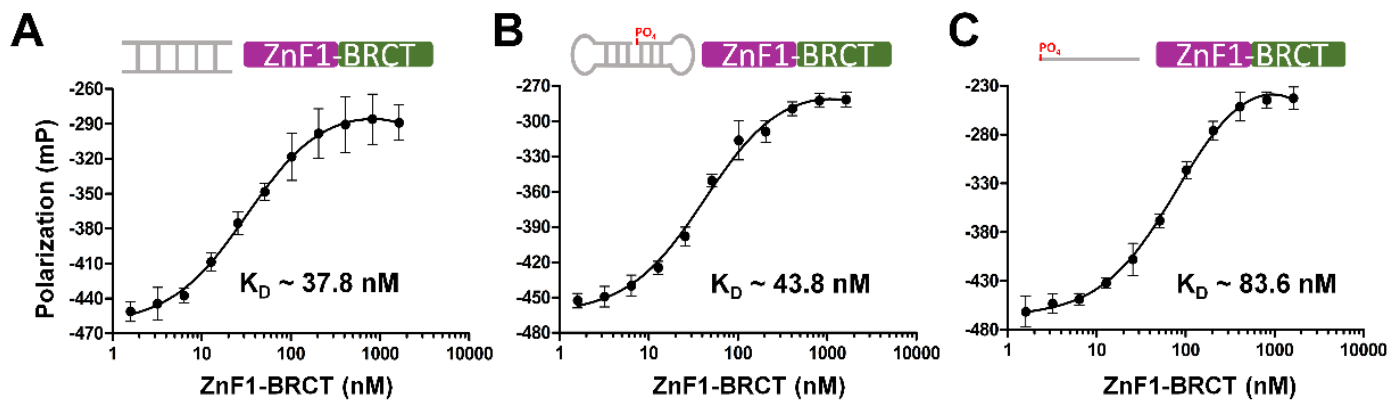

Figure 4. Fluorescence polarization binding studies of ZnF1-BRCT with (A) DSB DNA, (B) SSB DNA and (C) 5'P-ssSNA.

\section{Competition binding studies of PAR and different DNAs to PARP1 $1_{\mathrm{FL}}$}

Our FP binding studies shown that the PARP1 $1_{\mathrm{FL}}$ binds to DSB, SSB and 5'P-SSDNA with a $K_{D}$ of $9.9 \mathrm{nM}, 33.6 \mathrm{nM}$ and $29.6 \mathrm{nM}$ respectively (Supplementary Figure 7). The $K i$ of the competitor PAR was determined to be $68.1 \mathrm{nM}, 14.6 \mathrm{nM}$ and $6.4 \mathrm{nM}$, respectively, for DSB, SSB and 5'P-ssDNA bound to PARP1 FL (Figure 5 D-F).
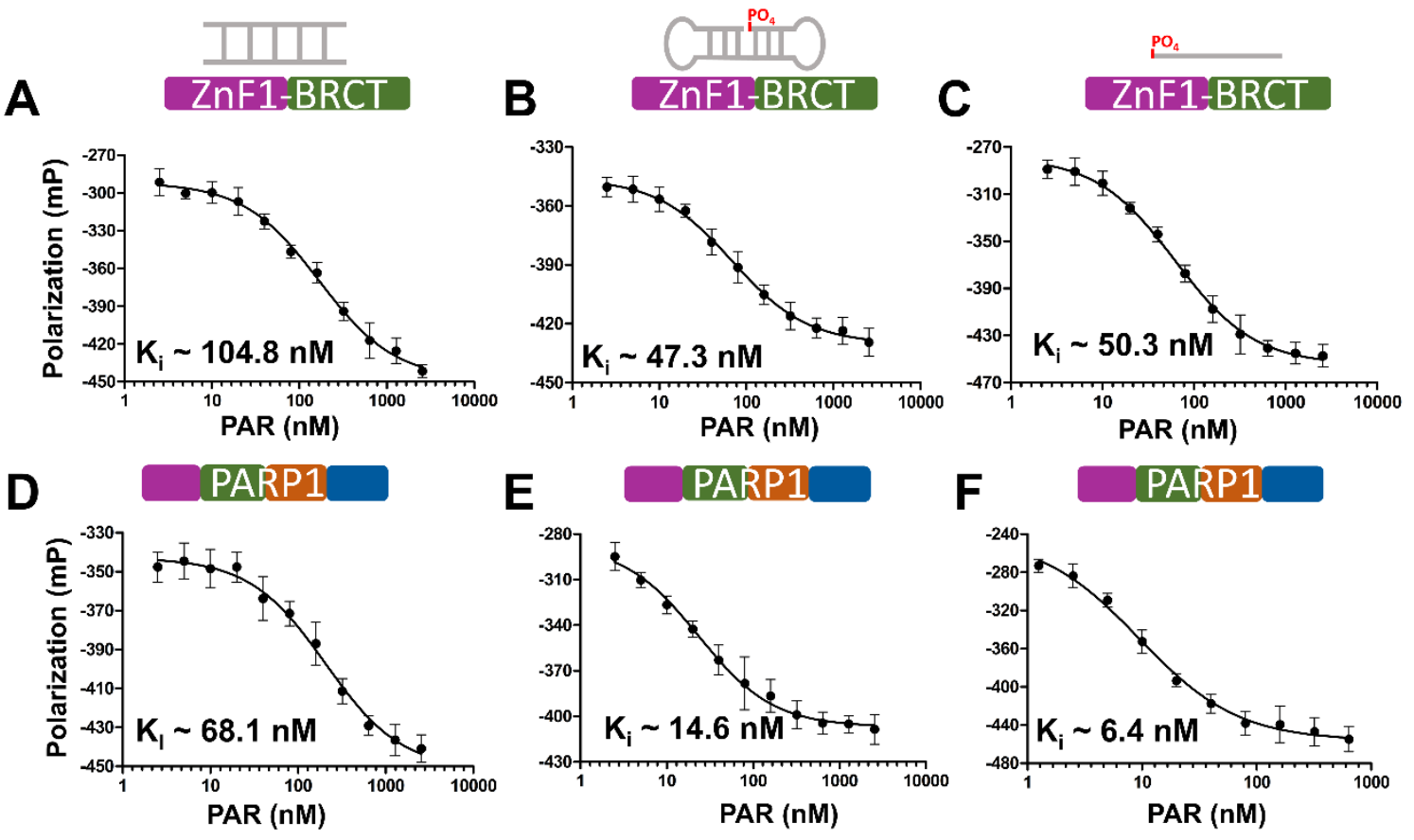

Figure 5. Fluorescence polarization based competition binding study. Competition binding study of unlabeled PAR for ZnF1-BRCT domains of PARP1 against fluorophore labelled (A) DSB DNA, (B) SSB DNA and (C) 5'P-ssDNA. Competition binding study of unlabeled PAR for PARP1 $1_{F L}$ against fluorophore labelled (D) DSB DNA, (E) SSB DNA and (F) 5'P-ssDNA.

\section{Effect of PAR on catalytic activity of PARP1}

Our PNC1-OPT based enzyme activity assay shows 4-fold increase in PARylation activity of PARP1 $1_{\mathrm{FL}}$ in the presence of PAR, compared to its absence after 30 minutes of incubation (Figure 6A).

\section{Effect of PAR on DNA dependent stimulation of PARP1's catalytic activity}


Our activity assay shows that SSDNA and SSB DNA independently stimulate PARP1FL activity by 10 and 12 folds, respectively (Figure 6). Though PAR stimulates the catalytic activity of the PARP1FL, the PAR dependent stimulation is significantly less (3-3.5 times) compared to ssDNA and SSB DNA dependent activation of the PARP1 $\mathrm{FL}$ (Figure 6). At the same time, PAR decelerates both the SSDNA and SSB DNA dependent stimulation of the PARP1's catalytic activity by $22 \%$ and $18 \%$, respectively (Figure 6B-C).
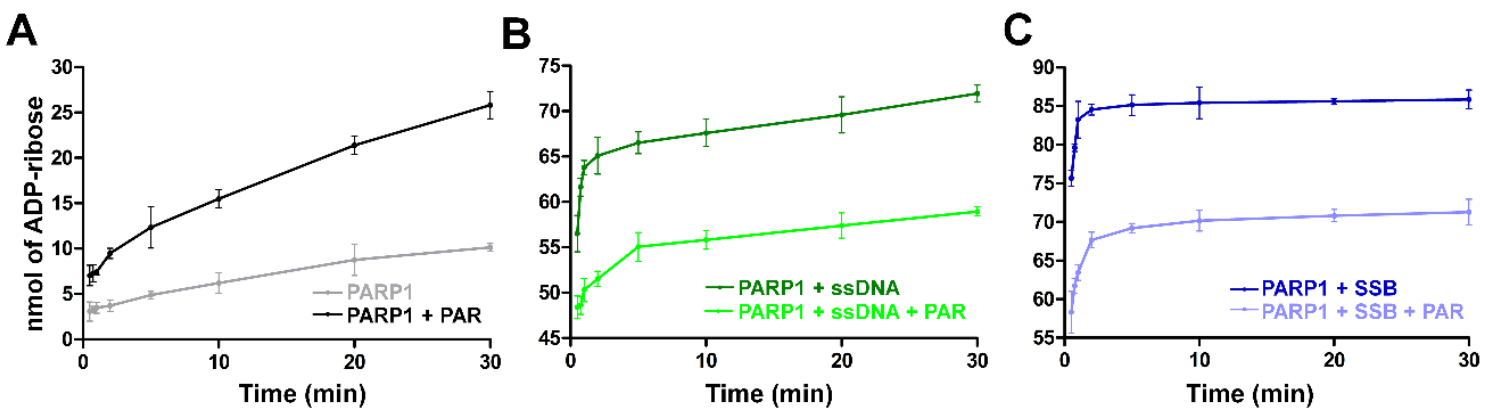

Figure 6. Colorimetry assay of PARP1 self-PARylation catalytic activity. Effect of PAR on PARP1 activity in (A) absence of DNA, and presence of (B) SSDNA and (C) SSB DNA. Error bars indicates the standard deviation of the three independent experiments.

\section{DISCUSSION}

PARP1 has been known for over six decades, yet its regulatory mechanism and binding partners have not been completely understood. In addition to till known regulators of PARP1, here we report that PARP1 is also regulated by its own catalytic product, PAR. Our studies reveal that PARP1 differentially recognize their binding partners, i.e., PAR and DNA, via dedicated domains. The investigation reveals $\mathrm{ZnF3}$, BRCT and WGR domains of PARP1 as a bonafide reader of PAR, whereas ZnF1 and $\mathrm{ZnF2}$ exhibited least to no affinity for the same (Figure 1C-E and Figure 2A-C). Contrarily, ZnF2 and ZnF1 have specific binding towards DNA, whereas ZnF3, BRCT and WGR domains do not bind to DNA (Supplementary Figure 5, 8 and 9). CAT domain, on other hand, show a weak affinity for PAR. These analyses suggest that, among reader domains, DNA reader domains are contiguous and are at the N-terminal of PARP1, similarly, PAR reader domains are also contiguous, but they are in the central region of the protein. The binding partners, other than damaged DNA and a few proteins (55), which could regulate the DNA binding and catalytic activities of PARP1 haven't been explored extensively. This study identifies the PAR reader domains of PARP1, and delineates the role of PAR in displacement of DNA bound to PARP1 and as a modulator of the catalytic activity of PARP1.

\section{ZnF domains of PARP1 differentially recognize PAR and DNAs}

$\mathrm{ZnF}$ domains of PARP1 have been known to recognize DNA breaks, where ZnF1 and $\mathrm{ZnF} 2$ together recognize SSB DNA, and $\mathrm{ZnF1}$ along with $\mathrm{ZnF3}$ recognize DSB DNA $(16,17)$. Additionally, $\mathrm{ZnF} 3$ has been reported to be involved in chromatin compaction and facilitates the inter-domain contacts for PARP1 activation rather than being directly involved in DNA binding (56). Our studies suggest that only ZnF1 and ZnF2 are directly involved in DNA binding, and not ZnF3 (Supplementary Figure 8). ZnF3, on the other hand, binds strongly to PAR (Figure 1E). Structural comparison of zinc fingers shows that $\mathrm{ZnF} 3$ is significantly different from $\mathrm{ZnF1}$ and $\mathrm{ZnF2}$ as it could not 
be superimposed on either of the two $\mathrm{ZnFs}$, whereas $\mathrm{ZnF} 1$ and $\mathrm{ZnF2}$ share a structural similarity with a RMSD of $0.6 \AA$ for $\mathrm{C} \alpha$ atoms (Supplementary Figure 10). Besides, canonical Zinc fingers, ZnF1 and ZnF2, have weak to no affinity for PAR (Figure 1CD). These data show that zinc fingers of PARP1 have different preference for their binding partners.

\section{Recognition of single strand DNA by PARP1 and its implications}

Recently it's been reported that PARP1 activity is greatly elevated by tens of kilobases behind DNA replication forks where un-ligated Okazaki fragment intermediates and DNA single strand gaps are observed in high frequency $(57,58)$. In addition, PARP1 is reported to be involved in replication fork remodelling when the DNA lesions are ahead of them $(59,60)$. In this study, for the first time, we have shown that PARP1, through its $\mathrm{ZnF1}$ and $\mathrm{ZnF} 2$ domains, binds to ssDNA with a high affinity as that of SSB and DSB DNA (Figure 3, Supplementary Figure 8) which supports the role of PARP1 in above phenomenon. Though, ssDNA is a structural analog of PAR (Supplementary Figure 1 ), both are recognized by different domains of PARP1.

\section{BRCT domain binds to PAR but not DNA}

BRCT domains of BRCA1 and MDC1 have been reported to recognize phosphorylated serine (Sph) while BRCT domains of XRCC1 and ligase 4 have been shown to recognize PAR, in micromolar binding affinity similar to BRCT domain of PARP1, as well as its monomeric unit, ADPr (29). Surprisingly, our ITC binding studies show that BRCT and other PAR binding domains of PARP1 are involved in recognizing PAR polymer but fails to bind ADPr monomer (Figure 1E; Figure 2A-B and Supplementary Figure 2) and also phosphorylated H2A.X peptide (data not shown). This suggests that BRCT and other PAR binding domains of PARP1 have a different PAR recognition mechanism compared to PAR binding domains of other proteins. Additionally, BRCT domain of PARP1 is also different from BRCT domain of other proteins which bind to Sph peptide. Our binding studies recapitulated previous reports that BRCT domain showed no binding to different DNAs (Supplementary Figure 9).

\section{WGR domain binds to PAR and assists the DSB DNA recognition}

The WGR and BRCT domains of PARP1 have not been functionally characterized. On the other hand, PARP2 WGR has been shown to be involved in recognition of DNA (32). Our study shows that PARP1 WGR does not bind to any of the tested DNAs (Supplementary Figure 5). Here, for the first time we show that, PARP1 WGR domain recognizes PAR with a binding affinity on par with PARP1 BRCT. Thus, our study opens a window for the characterization of WGR domain of PARP2 and PARP3 for recognition of PAR, and its possible implications in DNA repair and epigenetic processes.

Binding affinity of PARP1FL to DSB DNA is more than SSB DNA (Supplementary Figure $7 \mathrm{~A}, \mathrm{~B}$ ). In addition, binding affinity of PARP-1 $\mathrm{FL}$ is more than ZnF1-BRCT quadruple domain (Figure 4 and Supplementary Figure 7) which lacks WGR domain. These suggest that though WGR domain, standalone, does not bind to DSB DNA, it could be required for DNA dependent catalytic activity stimulation and may contribute to DNA binding in association with other domains of PARP1 (Figure 4 $A$ and Supplementary Figure 7 A). This study corroborates with the crystal structure of the $\mathrm{ZnF1}, \mathrm{ZnF3}$ and WGR-CAT domains of PARP1 assembled on the DSB DNA (PDB ID: 4DQY), where WGR domain has a network of interactions with the 5 ' terminal sequence of the DNA (16). In case of SSB, binding affinity of ZnF1-BRCT and PARPFL 
is almost same, indicating that WGR domain may not contribute for the recognition of SSB DNA (Figure 4 B and Supplementary Figure 7B).

\section{PARP1 reader domains exhibit higher binding affinity for PARylated protein compared PAR}

The BRCT and WGR domains of PARP1 not only bind to free PAR but also to PARylayed protein with higher affinities (Figure 2A,B,D,E) implicating that the recognition of PAR by PARP1 is not a random event but might have a biological significance. The higher binding affinity for PAR and PARylated protein by ZnF1-BRCT compared to individual domains (ZnF3 and BRCT) shows that these domains show synergism for PAR recognition (Figure 1E and Figure 2B,C,E,F).

\section{PAR allosterically regulate DNA binding to PARP1, and ZnF3-BRCT-WGR triple domains might play a major role in displacement of PARP1 from DNA in presence of PAR}

Since the binding of DNA to PARP1FL is tighter than $\mathrm{ZnF1-BRCT}$ quadruple domains of PARP1 (Figure 4 and Supplementary Figure 7), therefore, expectedly, Ki values for displacement of DNA from the PARP1FL-DNA complex by PAR should be more for displacement of DNA from ZnF1-BRCT-DNA complex. In contrast, higher concentrations of PAR were required for displacement of DNA from ZnF1-BRCT than PARP1 FL (Figure 5). Major difference between ZnF1-BRCT and PARP1 $1_{\mathrm{FL}}$ is PARP1 FL has an additional PAR binding domain WGR. Although WGR domain is not involved in DNA binding (Supplementary Figure 5), but it could negatively affect the damaged DNA binding to ZnFs, allosterically, through binding to PAR. Thus, PAR binding to ZnF3-BRCT-WGR triple domains could induce global conformational changes in the PARP1 making it incompetent to recognize DNA by $\mathrm{ZnF} 1$ and $\mathrm{ZnF} 2$ leading to dissociation of PARP1-DNA complex (Figure 7). Adaptation of compact structural conformation from the extended beads-on-string conformation by PARP1 upon DNA binding (16), supports our hypothesis of PAR-induced alternative global conformation in PARP1, though yet to be studied. It is noteworthy that certain PARP1 inhibitors (PARPi) bind to the catalytic domain of PARP1 and allosterically enhance either release or retention of PARP1 on the DNA (61-63). PAR may function analogously to the PARPi(s), which release the PARP1 from the bound DNA.

It has already been reported that self-PARylation of PARP1 leads to release of DNA from the PARP1 (64). Recently, through EMSA studies, PARP1FL has been shown to bind to PAR with a nanomolar binding affinity (65). Binding of PAR or PARylated proteins by the PAR-reader domains of PARP1 could lead to DNA dislodging from PARP1 itself. These phenomena are also supported by our studies which show that PAR binding domains of PARP1 exhibited higher affinity towards PARylated protein than PAR (Figure 2) and binding of PAR leads to DNA dissociation from PARP1 (Figure 5). 


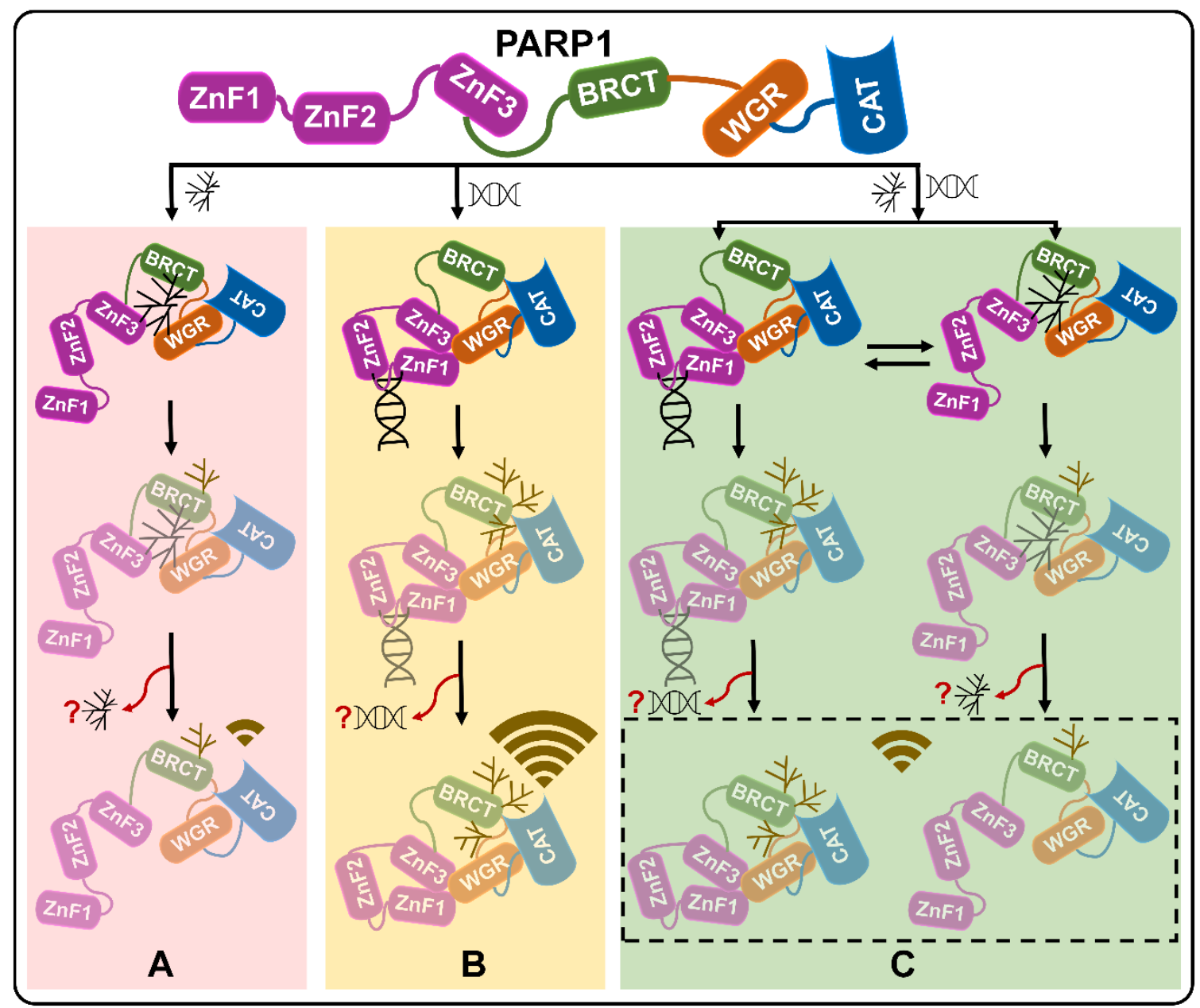

Figure 7. Schematic representation of proposed allosteric regulation of PARP1 by PAR and DNA. (A) Binding of PAR to ZnF3-WGR domains may lead to spatial reorganization of PARP1 domains to get into certain conformation that stimulates the catalytic activity of PARP1. (B) DNA binding induces conformational changes in the protein that leads to its maximal activation. (C) Binding of PAR and DNA to PARP1 might be non-competitive reversible that may lead to two different conformational outcomes, resulting in differential catalytic stimulation, which could be an average of PAR- and DNA-dependent catalytic stimulation of the PARP1. The displacement of DNA by the PAR from the DNA-PARP1 complex eventually retards the DNA dependent stimulation but at the same time PAR binding itself stimulate PARP1 activity, therefore the activation is modulated by cross talk between DNA and PAR binding to PARP1.

\section{PAR is a partial agonist of the PARP1}

Compared to DNA recognition, PAR is not only differentially recognized by PARP1 but also stimulates its enzymatic activity (Figure 6A). However, stimulation of activity is lesser than DNA dependent stimulation which suggests that PAR can be a partial agonist of PARP1, and difference in stimulation of activity supports that these polymers altogether induce different but catalytically competent global conformations of PARP1. This property of the PARP1 suggests that DNA independent stimulation of enzymatic activity may be required for PARylation of proteins involved in nuclear processes other than DNA repair (12).

\section{PAR retards the DNA dependent stimulation of PARP1's catalytic activity}


PAR and DNA independently stimulate the PARP1 catalytic activity (Figure 6), suggesting that PAR and DNA could synergistically stimulate the PARP1 activity. Surprisingly, instead of enhancing, PAR decelerates DNA dependent enzymatic activity of PARP1 (Figure 6B-C). For PAR being an agonist, the magnitude of retardation of DNA dependent PARP1 stimulation by PAR might be much more than what we observed in our experiments. In nutshell, PAR acts as both partial allosteric stimulator and partial allosteric inhibitor (partial antagonist) of PARP1 (Figure 7), and at the same time PAR may itself put a check on the amount of PAR which could be formed upon stimulation. Given that the PAR length and branching have specific functions in cellular physiology and stress response (22), our study suggests that PAR dependent regulation of PARP1 activity might have additional biological implications as well. Recently, it has been reported that protein factor, HPF1, stimulates the DNAdependent and independent self-PARylation of PARP1 and PARP2 as well as the trans-PARylation of histones in the complex with nucleosome (66). Likewise, PAR stimulates the self-PARylation of PARP1 but, unlike HPF1, it hampers the DNAdependent self-PARylation of PARP1. However, the effect of PAR or PARylated proteins on trans-PARylation activity of PARP1 on histones, other proteins or nucleic acid substrates of PARP1 needs to be addressed. Like Histone H4, PAR also stimulates PARP1's catalytic activity through binding to its C-terminal domains (67). However, it's not known whether H4 hampers DNA dependent stimulation of PARP1's activity like PAR.

\section{PARP1 is both writer and reader of PAR code}

Histone writers, erasers, and readers - the protein machineries that add, remove, or recognize post-translational modifications (PTMs)also known as histone or PTM codes, respectively - have become a cornerstone in understanding the role of epigenetics in transcription, DNA replication \& repair and splicing. PARylation, is an epigenetic PTM mark, and PAR code is involved in above process through chromatin remodeling, heterochromatin reorganization, histones exchange, etc. $(68,69)$. Several DNA methyltransferases, histone lysine methyl- and acetyl-transferases have both writer and reader domains of corresponding epigenetic mark, and both reading and writing of the marks direct a particular epigenetic outcome (70-72). Similarly, our studies establish that besides a PAR code writer domain, PARP1 also contains dedicated domains for reading PAR code. Therefore, our studies set the platform to understand the cross talk between reading and writing of a PAR code by the PARP1 on epigenetic gene regulation and/or DNA replication and repair.

Based on our findings we propose the allosteric regulation of PARP1 by its own catalytic product, PAR. Further, structural studies of PAR with PAR binding domains of PARP1 (individual or in combination) and PARP1FL would reveal mechanistic insights, and that could also help in designing of allosteric inhibitors or stimulators of PARP1. Moreover, these inhibitors would be very specific, since most of the available inhibitors (FDA approved or in clinical trials) target the NAD+ binding site, which could lead to non-specific targeting/ inhibition of other proteins of PARP family. Also, PAR recognition could be a kind of feedback regulation, which regulates the extent of PARylation by PARP1. This study also suggests the alternative pathway of stimulation of PARP1's catalytic activity in the nucleus of a cell independent of DNA damage signaling. 


\section{ACKNOWLEDGEMENT}

This work is supported by the 'Research and Development' scheme under 'Basic Research in Modern Biology' of Department of Biotechnology (DBT), Government of India. E.R. thanks the DBT and the Science and Engineering Research Board, Department of Science and Technology, Government of India for the Ramalingaswami re-entry fellowship and Early Career Research Award, respectively. W.D. thank University Grants Commission, Government of India for the fellowship. S.A. thank the Ministry of Human Resource Development, Government of India for the fellowship. Authors thank Dr. Jyotsnendu Giri, Biomedical Engineering Department, IIT Hyderabad and Dr. Basant Kumar Patel of Department of Biotechnology, IIT Hyderabad for providing the access to multimode microplate readers. Authors also thank Dr. John Pascal, Thomas Jefferson University, Philadelphia, USA for providing the pET28-a(+)-PARP2iso2 plasmid and Prof. Antonio Barrientos, University of Miami, FL, USA for providing pET41-b(+)-PNC1 plasmid.

\section{REFERENCE}

1. Tong,W.M., Cortes,U. and Wang,Z.Q. (2001) Poly(ADP-ribose) polymerase: a guardian angel protecting the genome and suppressing tumorigenesis. Biochim. Biophys. Acta, 1552, 27-37.

2. Haince,J.-F., McDonald,D., Rodrigue,A., Déry,U., Masson,J.-Y., Hendzel,M.J. and Poirier,G.G. (2008) PARP1-dependent Kinetics of Recruitment of MRE11 and NBS1 Proteins to Multiple DNA Damage Sites *. J. Biol. Chem., 283, 11971208.

3. Haince,J.-F., Kozlov,S., Dawson,V.L., Dawson,T.M., Hendzel,M.J., Lavin,M.F. and Poirier,G.G. (2007) Ataxia Telangiectasia Mutated (ATM) Signaling Network Is Modulated by a Novel Poly(ADP-ribose)-dependent Pathway in the Early Response to DNA-damaging Agents *. J. Biol. Chem., 282, 16441-16453.

4. Masson,M., Niedergang,C., Schreiber,V., Muller,S., Menissier-de Murcia,J. and de Murcia,G. (1998) XRCC1 Is Specifically Associated with Poly(ADP-Ribose) Polymerase and Negatively Regulates Its Activity following DNA Damage. Mol. Cell. Biol., 18, 3563-3571.

5. Liu,Y., Prasad,R., Beard,W.A., Kedar,P.S., Hou,E.W., Shock,D.D. and Wilson,S.H. (2007) Coordination of Steps in Single-nucleotide Base Excision Repair Mediated by Apurinic/Apyrimidinic Endonuclease 1 and DNA Polymerase $\beta$ *. J. Biol. Chem., 282, 13532-13541.

6. d'AMOURS,D., DESNOYERS,S., d'SILVA,I. and POIRIER,G.G. (1999) Poly(ADPribosyl)ation reactions in the regulation of nuclear functions. Biochem. J., $\mathbf{3 4 2}$, 249-268.

7. Huletsky,A., Murcia,G. de, Muller,S., Hengartner,M., Ménard,L., Lamarre,D. and Poirier,G.G. (1989) The Effect of poly(ADP-ribosyl)ation on Native and H1depleted Chromatin: A Role of Poly(ADP-ribosyl)ation on Core Nucleosome Structure. J. Biol. Chem., 264, 8878-8886.

8. Poirier,G.G., de Murcia,G., Jongstra-Bilen,J., Niedergang,C. and Mandel,P. (1982) Poly(ADP-ribosyl)ation of polynucleosomes causes relaxation of chromatin structure. Proc. Natl. Acad. Sci. U. S. A., 79, 3423-3427.

9. Kraus,W.L. (2008) Transcriptional control by PARP-1: chromatin modulation, enhancer-binding, coregulation, and insulation. Curr. Opin. Cell Biol., 20, 294302. 
10. Wesierska-gadek,J. and Schmid,G. Poly(ADP-ribose) polymerase-1 regulates the stability of the wild-type p53.

11. Hassa,P.O., Covic,M., Hasan,S., Imhof,R. and Hottiger,M.O. (2001) The Enzymatic and DNA Binding Activity of PARP-1 Are Not Required for NF-kB Coactivator Function *. J. Biol. Chem., 276, 45588-45597.

12. Taniguchi,T., Suzuki,S. and Shizuta,Y. (1985) Poly (ADP-ribosyl)ation of RNA polymerase II from wheat germ. Biochem. Biophys. Res. Commun., 127, 526532.

13. Chaitanya,G.V., Alexander,J.S. and Babu,P.P. (2010) PARP-1 cleavage fragments: signatures of cell-death proteases in neurodegeneration. Cell Commun. Signal. CCS, 8, 31.

14. Fu,L., Wang,S., Wang,X., Wang,P., Zheng,Y., Yao,D., Guo,M., Zhang,L. and Ouyang,L. (2016) Crystal structure-based discovery of a novel synthesized PARP1 inhibitor (OL-1) with apoptosis-inducing mechanisms in triple-negative breast cancer. Sci. Rep., 6, 3.

15. Lilyestrom,W., van der Woerd,M.J., Clark,N. and Luger,K. (2010) Structural and Biophysical Studies of Human PARP-1 in Complex with Damaged DNA. J. Mol. Biol., 395, 983-994.

16. Langelier,M.-F., Planck,J.L., Roy,S. and Pascal,J.M. (2012) Structural basis for DNA damage-dependent poly(ADP-ribosyl)ation by human PARP-1. Science, 336, 728-732.

17. Eustermann,S., Wu,W.-F., Langelier,M.-F., Yang,J.-C., Easton,L.E., Riccio,A.A., Pascal,J.M. and Neuhaus,D. (2015) Structural Basis of Detection and Signaling of DNA Single-Strand Breaks by Human PARP-1. Mol. Cell, 60, 742-754.

18. Langelier,M.-F., Planck,J.L., Roy,S. and Pascal,J.M. (2011) Crystal Structures of Poly(ADP-ribose) Polymerase-1 (PARP-1) Zinc Fingers Bound to DNA: STRUCTURAL AND FUNCTIONAL INSIGHTS INTO DNA-DEPENDENT PARP-1 ACTIVITY*. J. Biol. Chem., 286, 10690-10701.

19. Ali,A.A.E., Timinszky,G., Arribas-Bosacoma,R., Kozlowski,M., Hassa,P.O., Hassler,M., Ladurner,A.G., Pearl,L.H. and Oliver,A.W. (2012) The zinc-finger domains of PARP1 cooperate to recognize DNA strand breaks. Nat. Struct. Mol. Biol., 19, 685-692.

20. Dawicki-McKenna,J.M., Langelier,M.-F., DeNizio,J.E., Riccio,A.A., Cao,C.D., Karch,K.R., McCauley,M., Steffen,J.D., Black,B.E. and Pascal,J.M. (2015) PARP-1 Activation Requires Local Unfolding of an Autoinhibitory Domain. Mol. Cell, 60, 755-768.

21. Langelier,M.-F., Zandarashvili,L., Aguiar,P.M., Black,B.E. and Pascal,J.M. (2018) $\mathrm{NAD}+$ analog reveals PARP-1 substrate-blocking mechanism and allosteric communication from catalytic center to DNA-binding domains. Nat. Commun., 9, 844.

22. Aberle,L., Krüger,A., Reber,J.M., Lippmann,M., Hufnagel,M., Schmalz,M., Trussina,I.R.E.A., Schlesiger,S., Zubel,T., Schütz,K., et al. (2020) PARP1 catalytic variants reveal branching and chain length-specific functions of poly(ADP-ribose) in cellular physiology and stress response. Nucleic Acids Res., 48, 10015-10033.

23. Krishnakumar,R. and Kraus,W.L. (2010) The PARP Side of the Nucleus: Molecular Actions, Physiological Outcomes, and Clinical Targets. Mol. Cell, 39, 8-24.

24. Leidecker,O., Bonfiglio,J.J., Colby,T., Zhang,Q., Atanassov,I., Zaja,R., Palazzo,L., Stockum,A., Ahel,I. and Matic,I. (2016) Serine is a new target residue for endogenous ADP-ribosylation on histones. Nat. Chem. Biol., 12, 998-1000. 
25. Leslie Pedrioli,D.M., Leutert,M., Bilan,V., Nowak,K., Gunasekera,K., Ferrari,E., Imhof,R., Malmström,L. and Hottiger,M.O. (2018) Comprehensive ADPribosylome analysis identifies tyrosine as an ADP-ribose acceptor site. EMBO Rep., 19, e45310.

26. Messner,S., Altmeyer,M., Zhao,H., Pozivil,A., Roschitzki,B., Gehrig,P., Rutishauser,D., Huang,D., Caflisch,A. and Hottiger,M.O. (2010) PARP1 ADPribosylates lysine residues of the core histone tails. Nucleic Acids Res., 38, 6350-6362.

27. Vivelo,C.A. and Leung,A.K.L. (2015) Proteomics approaches to identify mono(ADP-ribosyl)ated and poly(ADP-ribosyl)ated proteins. Proteomics, 15, 203217.

28. Teloni,F. and Altmeyer,M. (2016) Readers of poly(ADP-ribose): designed to be fit for purpose. Nucleic Acids Res., 44, 993-1006.

29. Li,M., Lu,L.-Y., Yang,C.-Y., Wang,S. and Yu,X. (2013) The FHA and BRCT domains recognize ADP-ribosylation during DNA damage response. Genes Dev., 27, 1752-1768.

30. Chen,Q., Kassab,M.A., Dantzer,F. and Yu,X. (2018) PARP2 mediates branched poly ADP-ribosylation in response to DNA damage. Nat. Commun., 9, 3233.

31. Fouquerel,E. and Sobol,R.W. (2014) ARTD1 (PARP1) activation and NAD(+) in DNA repair and cell death. DNA Repair, 23, 27-32.

32. Obaji,E., Haikarainen,T. and Lehtiö,L. (2016) Characterization of the DNA dependent activation of human ARTD2/PARP2. Sci. Rep., 6, 34487.

33. Lonskaya,I., Potaman,V.N., Shlyakhtenko,L.S., Oussatcheva,E.A., Lyubchenko,Y.L. and Soldatenkov,V.A. (2005) Regulation of Poly(ADP-ribose) Polymerase-1 by DNA Structure-specific Binding*. J. Biol. Chem., 280, 1707617083.

34. Melikishvili,M., Chariker,J.H., Rouchka,E.C. and Fondufe-Mittendorf,Y.N. (2017) Transcriptome-wide identification of the RNA-binding landscape of the chromatin-associated protein PARP1 reveals functions in RNA biogenesis. Cell Discov., 3, 17043.

35. Matveeva,E., Maiorano,J., Zhang,Q., Eteleeb,A.M., Convertini,P., Chen,J., Infantino,V., Stamm,S., Wang,J., Rouchka,E.C., et al. (2016) Involvement of PARP1 in the regulation of alternative splicing. Cell Discov., 2, 15046.

36. Nakamoto,M.Y., Rudolph,J., Wuttke,D.S. and Luger,K. (2019) Nonspecific Binding of RNA to PARP1 and PARP2 Does Not Lead to Catalytic Activation. Biochemistry, 58, 5107-5111.

37. Kun,E., Kirsten,E., Mendeleyev,J. and Ordahl,C.P. (2004) Regulation of the enzymatic catalysis of poly(ADP-ribose) polymerase by dsDNA, polyamines, $\mathrm{Mg} 2+, \mathrm{Ca} 2+$, histones $\mathrm{H} 1$ and $\mathrm{H} 3$, and ATP. Biochemistry, 43, 210-216.

38. Gibbs-Seymour,I., Fontana,P., Rack,J.G.M. and Ahel,I. (2016) HPF1/C4orf27 Is a PARP-1-Interacting Protein that Regulates PARP-1 ADP-Ribosylation Activity. Mol. Cell, 62, 432-442.

39. Ouararhni,K., Hadj-Slimane,R., Ait-Si-Ali,S., Robin,P., Mietton,F., Harel-Bellan,A., Dimitrov,S. and Hamiche,A. (2006) The histone variant mH2A1.1 interferes with transcription by down-regulating PARP-1 enzymatic activity. Genes Dev., 20, 3324-3336.

40. Masaoka,A., Gassman,N.R., Kedar,P.S., Prasad,R., Hou,E.W., Horton,J.K., Bustin,M. and Wilson,S.H. (2012) HMGN1 protein regulates poly(ADP-ribose) polymerase-1 (PARP-1) self-PARylation in mouse fibroblasts. J. Biol. Chem., 287, 27648-27658. 
41. Fischer,J.M.F., Popp,O., Gebhard,D., Veith,S., Fischbach,A., Beneke,S., Leitenstorfer,A., Bergemann,J., Scheffner,M., Ferrando-May,E., et al. (2014) Poly(ADP-ribose)-mediated interplay of XPA and PARP1 leads to reciprocal regulation of protein function. FEBS J., 281, 3625-3641.

42. Noren Hooten,N., Fitzpatrick,M., Kompaniez,K., Jacob,K.D., Moore,B.R., Nagle,J., Barnes,J., Lohani,A. and Evans,M.K. (2012) Coordination of DNA repair by NEIL1 and PARP-1: a possible link to aging. Aging, 4, 674-685.

43. Noren Hooten,N., Kompaniez,K., Barnes,J., Lohani,A. and Evans,M.K. (2011) Poly(ADP-ribose) polymerase 1 (PARP-1) binds to 8-oxoguanine-DNA glycosylase (OGG1). J. Biol. Chem., 286, 44679-44690.

44. Robu,M., Shah,R.G., Petitclerc,N., Brind'Amour,J., Kandan-Kulangara,F. and Shah,G.M. (2013) Role of poly(ADP-ribose) polymerase-1 in the removal of UVinduced DNA lesions by nucleotide excision repair. Proc. Natl. Acad. Sci. U. S. A., 110, 1658-1663.

45. Masutani,M., Nozaki,T., Nishiyama,E., Shimokawa,T., Tachi,Y., Suzuki,H., Nakagama,H., Wakabayashi,K. and Sugimura,T. (1999) Function of poly(ADPribose) polymerase in response to DNA damage: gene-disruption study in mice. Mol. Cell. Biochem., 193, 149-152.

46. Cohen-Armon,M., Visochek,L., Rozensal,D., Kalal,A., Geistrikh,I., Klein,R., Bendetz-Nezer,S., Yao,Z. and Seger,R. (2007) DNA-independent PARP-1 activation by phosphorylated ERK2 increases Elk1 activity: a link to histone acetylation. Mol. Cell, 25, 297-308.

47. Sun,X., Fu,K., Hodgson,A., Wier,E.M., Wen,M.G., Kamenyeva,O., Xia,X., Koo,L.Y. and Wan,F. (2016) Sam68 Is Required for DNA Damage Responses via Regulating Poly(ADP-ribosyl)ation. PLoS Biol., 14, e1002543.

48. Alemasova,E.E., Naumenko,K.N., Kurgina,T.A., Anarbaev,R.O. and Lavrik,O.I. (2018) The multifunctional protein YB-1 potentiates PARP1 activity and decreases the efficiency of PARP1 inhibitors. Oncotarget, 9, 23349-23365.

49. Piao,L., Nakagawa,H., Ueda,K., Chung,S., Kashiwaya,K., Eguchi,H., Ohigashi,H., Ishikawa,O., Daigo,Y., Matsuda,K., et al. (2011) C12orf48, termed PARP-1 binding protein, enhances poly(ADP-ribose) polymerase-1 (PARP-1) activity and protects pancreatic cancer cells from DNA damage. Genes. Chromosomes Cancer, 50, 13-24.

50. Fischbach,A., Krüger,A., Hampp,S., Assmann,G., Rank,L., Hufnagel,M., Stöckl,M.T., Fischer,J.M.F., Veith,S., Rossatti,P., et al. (2018) The C-terminal domain of p53 orchestrates the interplay between non-covalent and covalent poly(ADP-ribosyl)ation of p53 by PARP1. Nucleic Acids Res., 46, 804-822.

51. Langelier,M.-F., Planck,J.L., Servent,K.M. and Pascal,J.M. (2011) Purification of human PARP-1 and PARP-1 domains from Escherichia coli for structural and biochemical analysis. Methods Mol. Biol. Clifton NJ, 780, 209-226.

52. Edwards,A.D., Marecki,J.C., Byrd,A.K., Gao,J. and Raney,K.D. (2021) GQuadruplex loops regulate PARP-1 enzymatic activation. Nucleic Acids Res., 49, 416-431.

53. Lin,K.Y., Huang,D. and Kraus,W.L. (2018) Generating Protein-Linked and ProteinFree Mono-, Oligo-, and Poly(ADP-Ribose) In Vitro. Methods Mol. Biol. Clifton NJ, 1813, 91-108.

54. Hubbard,B.P. and Sinclair,D.A. (2013) Measurement of sirtuin enzyme activity using a substrate-agnostic fluorometric nicotinamide assay. Methods Mol. Biol. Clifton NJ, 1077, 167-177. 
55. Alemasova,E.E. and Lavrik,O.I. (2019) Poly(ADP-ribosyl)ation by PARP1: reaction mechanism and regulatory proteins. Nucleic Acids Res., 47, 3811-3827.

56. Langelier,M.-F., Servent,K.M., Rogers,E.E. and Pascal,J.M. (2008) A third zincbinding domain of human poly(ADP-ribose) polymerase-1 coordinates DNAdependent enzyme activation. J. Biol. Chem., 283, 4105-4114.

57. Vaitsiankova,A., Burdova,K., Hanzlikova,H. and Caldecott,K.W. (2021) PARP Inhibition Impedes the Maturation of Nascent DNA Strands During DNA Replication.

58. Hanzlikova,H., Kalasova,I., Demin,A.A., Pennicott,L.E., Cihlarova,Z. and Caldecott,K.W. (2018) The Importance of Poly(ADP-Ribose) Polymerase as a Sensor of Unligated Okazaki Fragments during DNA Replication. Mol. Cell, 71, 319-331.e3.

59. Ronson,G.E., Piberger,A.L., Higgs,M.R., Olsen,A.L., Stewart,G.S., McHugh,P.J., Petermann,E. and Lakin,N.D. (2018) PARP1 and PARP2 stabilise replication forks at base excision repair intermediates through Fbh1-dependent Rad51 regulation. Nat. Commun., 9, 746.

60. Liptay,M., Barbosa,J.S. and Rottenberg,S. (2020) Replication Fork Remodeling and Therapy Escape in DNA Damage Response-Deficient Cancers. Front. Oncol., 10, 670.

61. Zandarashvili,L., Langelier,M.-F., Velagapudi,U.K., Hancock,M.A., Steffen,J.D., Billur,R., Hannan,Z.M., Wicks,A.J., Krastev,D.B., Pettitt,S.J., et al. (2020) Structural basis for allosteric PARP-1 retention on DNA breaks. Science, 368, eaax6367.

62. Kim,C., Wang,X.-D. and Yu,Y. (2020) PARP1 inhibitors trigger innate immunity via PARP1 trapping-induced DNA damage response. eLife, 10.7554/eLife.60637.

63. Rudolph,J., Roberts,G. and Luger,K. (2021) Histone Parylation factor 1 contributes to the inhibition of PARP1 by cancer drugs. Nat. Commun., 12, 736.

64. Langelier,M.-F., Riccio,A.A. and Pascal,J.M. (2014) PARP-2 and PARP-3 are selectively activated by 5' phosphorylated DNA breaks through an allosteric regulatory mechanism shared with PARP-1. Nucleic Acids Res., 42, 77627775.

65. Dasovich,M., Beckett,M.Q., Bailey,S., Ong,S.-E., Greenberg,M.M. and Leung,A.K.L. (2021) Identifying Poly(ADP-ribose)-Binding Proteins with Photoaffinity-Based Proteomics. J. Am. Chem. Soc., 143, 3037-3042.

66. Kurgina,T.A., Moor,N.A., Kutuzov,M.M., Naumenko,K.N., Ukraintsev,A.A. and Lavrik,O.I. (2021) Dual function of HPF1 in the modulation of PARP1 and PARP2 activities. Commun. Biol., 4, 1259.

67. Thomas,C., Ji,Y., Wu,C., Datz,H., Boyle,C., Macleod,B., Patel,S., Ampofo,M., Currie,M., Harbin,J., et al. (2019) Hit and run versus long-term activation of PARP-1 by its different domains fine-tunes nuclear processes. Proc. Natl. Acad. Sci. U. S. A., 116, 9941-9946.

68. Quénet,D., El Ramy,R., Schreiber,V. and Dantzer,F. (2009) The role of poly(ADPribosyl)ation in epigenetic events. Int. J. Biochem. Cell Biol., 41, 60-65.

69. Ummarino,S., Hausman,C. and Di Ruscio,A. (2021) The PARP Way to Epigenetic Changes. Genes, 12, 446.

70. Rothbart,S.B., Krajewski,K., Nady,N., Tempel,W., Xue,S., Badeaux,A.I., BarsyteLovejoy,D., Martinez,J.Y., Bedford,M.T., Fuchs,S.M., et al. (2012) Association of UHRF1 with methylated H3K9 directs the maintenance of DNA methylation. Nat. Struct. Mol. Biol., 19, 1155-1160. 
71. Torres,I.O. and Fujimori,D.G. (2015) Functional coupling between writers, erasers and readers of histone and DNA methylation. Curr. Opin. Struct. Biol., 35, 6875.

72. Xi,Q., Wang,Z., Zaromytidou,A.-I., Zhang,X.H.-F., Chow-Tsang,L.-F., Liu,J.X., Kim,H., Barlas,A., Manova-Todorova,K., Kaartinen,V., et al. (2011) A Poised Chromatin Platform for TGF- $\beta$ Access to Master Regulators. Cell, 147, $1511-$ 1524. 